\title{
Influence of V5/6-His Tag on the Properties of Gap Junction Channels Composed of Connexin43, Connexin40 or Connexin45
}

\author{
Thomas Desplantez $\cdot$ Deborah Halliday $\cdot$ \\ Emmanuel Dupont $\cdot$ Nicholas J. Severs • \\ Robert Weingart
}

Received: 18 March 2010/Accepted: 21 February 2011/Published online: 19 March 2011

(C) The Author(s) 2011. This article is published with open access at Springerlink.com

\begin{abstract}
HeLa cells expressing wild-type connexin43, connexin40 or connexin 45 and connexins fused with a V5/ 6-His tag to the carboxyl terminus (CT) domain (Cx43-tag, Cx40-tag, Cx45-tag) were used to study connexin expression and the electrical properties of gap junction channels. Immunoblots and immunolabeling indicated that tagged connexins are synthesized and targeted to gap junctions in a similar manner to their wild-type counterparts. Voltageclamp experiments on cell pairs revealed that tagged connexins form functional channels. Comparison of multichannel and single-channel conductances indicates that tagging reduces the number of operational channels, implying interference with hemichannel trafficking, docking and/or channel opening. Tagging provoked connexinspecific effects on multichannel and single-channel properties. The Cx43-tag was most affected and the Cx45-tag, least. The modifications included (1) $V_{\mathrm{j}}$-sensitive gating of $I_{\mathrm{j}}\left(V_{\mathrm{j}}\right.$, gap junction voltage; $I_{\mathrm{j}}$, gap junction current), (2)
\end{abstract}

Electronic supplementary material The online version of this article (doi:10.1007/s00232-011-9352-z) contains supplementary material, which is available to authorized users.

T. Desplantez $\cdot$ R. Weingart $(\varangle)$

Institute of Physiology, University of Bern, Bühlplatz 5, 3012 Bern, Switzerland

e-mail: weingart@pyl.unibe.ch

Present Address:

T. Desplantez - D. Halliday · E. Dupont - N. J. Severs

National Heart and Lung Institute, Imperial College London,

London SW3 6LY, UK

Present Address:

E. Dupont

Post Graduate School of Medicine, Faculty of Health and Medical Sciences, University of Surrey Guildford, Surrey GU27XH, UK contribution and (3) kinetics of $I_{\mathrm{j}}$ deactivation and (4) single-channel conductance. The first three reflect alterations of fast $V_{\mathrm{j}}$ gating. Hence, they may be caused by structural and/or electrical changes on the CT that interact with domains of the amino terminus and cytoplasmic loop. The fourth reflects alterations of the ion-conducting pathway. Conceivably, mutations at sites remote from the channel pore, e.g., 6-His-tagged CT, affect protein conformation and thus modify channel properties indirectly. Hence, V5/6-His tagging of connexins is a useful tool for expression studies in vivo. However, it should not be ignored that it introduces connexin-dependent changes in both expression level and electrophysiological properties.

Keywords Gap junction - Connexin - Electrophysiology · Immunocytochemistry $\cdot$ V5/6-His tag $\cdot$ Fusion protein

\section{Introduction}

Gap junction channels (GJCs) provide a direct pathway for the rapid exchange of cytosolic signals between adjoining cells. They result from the docking of two hemichannels (HCs) arranged in series. Each $\mathrm{HC}$ or connexon consists of six subunits composed of connexin $(\mathrm{Cx})$ molecules (Bruzzone et al. 1996). Each Cx molecule crosses the cell membrane four times, thus forming four transmembrane domains (M1-M4), two extracellular loops (E1 and E2), a cytoplasmic loop (CL) and an intracellular amino and carboxyl terminus (NT and CT). More than 20 different mammalian Cxs have been identified (Sohl and Willecke 2004), three of which-Cx43, Cx40 and Cx45-are expressed in cardiac myocytes. In addition, a further $\mathrm{Cx}$, Cx30.2, has been reported in mouse atrioventricular (AV) node myocytes (Kreuzberg et al. 2005); but the orthologue 
of this $\mathrm{Cx}(\mathrm{Cx} 31.9)$ is not detectable in human AV nodes (Kreuzberg et al. 2009). Each isoform exhibits a different expression pattern (Van Veen et al. 2001; Severs et al. 2004) and forms channels of distinct electrical and diffusional properties (Harris 2001; Kreuzberg et al. 2005).

Recombinant proteins are versatile tools in biological research. To facilitate their use in studies on the synthesis, expression and structure or function of proteins, easy and reliable chasing methods have been developed. For example, epitope tagging enables the use of different antibodies, and addition of sequences permits the use of defined protocols for protein purification (GST, V5/6xHis) (Terpe 2003). To examine the channel structural makeup and properties such as localization, trafficking, turnover and permeability, reliable detection and purification of Cxs are crucial. Tagging of Cxs with recognizable moieties, such as fluorescent GFP, CFP or YFP, has become a useful approach. His tag, a hexa moiety, has been introduced for easy separation of proteins by affinity chromatography using $\mathrm{Ni}^{2+}$-chelating resins (Terpe 2003). The latter has also been used to study molecular interactions between Cxs (Martinez et al. 2002) and with associated molecules such as ZO-1 (Toyofuku et al. 1998; Hunter et al. 2005).

It is frequently assumed that addition of a V5/6-His tag to a protein has little or no effect on function. However, this has yet to be confirmed experimentally. In the present study focusing on the major cardiac Cxs (Cx40, Cx43 and $\mathrm{Cx} 45$ ), we tested this assumption by means of electrophysiological measurements.

\section{Methods}

\section{His Tagging of Connexins}

The tag used for this work contains 31 residues including a 14-residue epitope, readily detectable by a sensitive anti-V5 antibody, and a stretch of histidines to facilitate purification with $\mathrm{Ni}^{2+}$-chelating resins (hexa moiety, $M_{\mathrm{r}}=0.93 \mathrm{kDa}$ ). In order to add the molecular V5/6-His tag (Invitrogen, Carlsbad, CA) at the end of the Cxs, we first amplified them by PCR using primers that contain restriction sites for directional cloning and in-frame insertion into pcDNA3.1 V5/His. The templates used were pBLUESCRIPT containing rat Cx43 (GJA1; www.genenames.org/genefamily/gj. php; gift from E. C. Beyer) or mouse Cx40 and Cx45 (GJA5, GJC1; gifts from K. Willecke). The forward primer for Cx43 adds a BamH1 site (ggatcc) three bases before the start codon on the natural rat $\mathrm{Cx} 43$ sequence, and the forward primers for Cx40 and Cx45 add a Hind 3 site (aagctt) three bases before the start codon on the natural mouse sequences. The reverse primers all include an Xho1 site that removes the stop codon (all amino acids of Cxs are retained) and allows subcloning in-frame to version A of pcDNA3.1V5/6-His. These plasmids were tested, and, as in many transfection experiments using conventional plasmids, expression of the transfected Cxs was heterogeneous, with large areas of cells displaying no labeling. To overcome this problem, which artificially decreases the incidence of coupling (as some cell pairs do not express the transfected $\mathrm{Cx}$ and do not show junctional communication), we recloned the tagged $\mathrm{Cx}$ in pIRES Hygro (Clontech, Palo Alto, CA; see generic map Fig. 1), allowing a single mRNA to code for both connexin and hygromycin resistance, therefore selecting out the nonexpressing cells. This was done using similar primers as above but containing an EcoRV site instead of the BamH1/Hind3 and a primer specific for the molecular tag that includes a Not1 site (common for the three tagged Cxs). The templates were pcDNA3.1 constructs, described above. The PCR product was thereafter cloned into pIRES Hygro (Clontech, see generic map Fig. 1). For ligation, all PCR products and all plasmids were cut with the appropriate restriction enzyme and gel-purified on low-melt agarose. All ligations were done using the T4 ligase. Transformation of Escherichia coli HB101, selection on ampicillin plates and plasmid purification (mini and large prep) were done as described previously (Sambrook et al. 1989).

\section{Cell Cultures and Transfection}

Human HeLa cells (ATCC code CCL2) were grown in DMEM supplemented with $10 \%$ FBS, $100 \mu \mathrm{g} / \mathrm{ml}$ streptomycin and $100 \mathrm{U} / \mathrm{ml}$ penicillin. Cells were kept in an incubator at $37^{\circ} \mathrm{C}\left(5 \% \mathrm{CO}_{2}, 95 \%\right.$ ambient air $)$ and passaged weekly. Transfections were made in serum-free DMEM

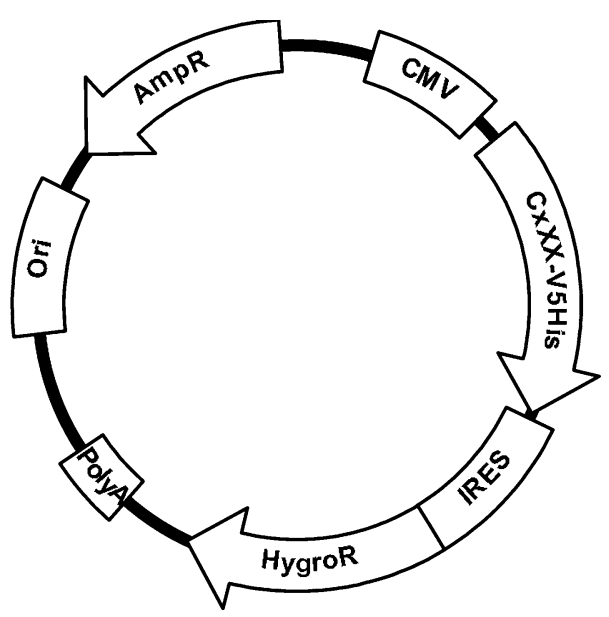

Fig. 1 Generic plasmid map of the construct used. The CMV promoter generates a bicistronic mRNA that codes for a $\mathrm{Cx}(\mathrm{CxXX}$ : $\mathrm{XX}=40,43$ or 45 ) and hygromycin $\mathrm{B}$ resistance 
using lipofectin, as recommended by the manufacturer. After 10-15 days of selection with $250 \mu \mathrm{g} / \mathrm{ml}$ hygromycin $\mathrm{B}$, individual clones were picked up using cloning cylinders, sealed to the dish with sterile vacuum grease, and trypsin digested. Transfectants were maintained in DMEM containing $250 \mu \mathrm{g} / \mathrm{ml}$ hygromycin B. To carry out experiments, cells were seeded onto sterile glass coverslips placed in Petri dishes. They were ready for use 1-2 days after plating. In the case of mixed cultures (see electronic supplement), prior to plating one type of cell was labeled with a fluorescent dye $(2.5 \mu \mathrm{M}$ 5-chloromethylfluorescein diacetate, $1 \mathrm{~h}$; Molecular Probes, Eugene, OR).

\section{Sample Preparation and Western Blotting}

Sample preparation and Western blotting methods were as previously described (Dupont et al. 1988, 2001). Briefly, cell monolayers were lysed in SB20 (0.1 M Tris [pH 6.8], $10 \mathrm{mM}$ EDTA, 20\% SDS) and sonicated, protein content was assayed using the Bio-Rad (Richmond, CA) DC protein assay and 2-mercaptoethanol was added to a final concentration of $2.5 \%$. Five micrograms of total protein were loaded per lane, and samples were run on $12.5 \%$ SDS polyacrylamide gels and electrophoretically tank-transferred to PVDF membrane (Immobilon-P). Replicas were incubated with primary antibody (anti-V5, Invitrogen) and then with alkaline phosphatase-conjugated goat anti-mouse antibody (Pierce, Rockford, IL). Enzymatic activity was revealed using NBT/BCIP substrate solution.

\section{Immunofluorescence Labeling}

Transfected cells were cultured on round glass coverslips at the bottom of culture wells (24-well plates). Labeling was carried out as described previously (Coppen et al. 1998). Briefly, cells were rinsed in $\mathrm{Ca}^{2+}$ containing PBS, fixed in cold methanol and rinsed again prior to blocking in a solution of PBS/1\% BSA. Slides were then incubated with the primary antibody of choice (rabbit anti-Cx40 S15C[R83]) (Severs et al. 2001), mouse monoclonal antiCx43 (MAB3068; Chemicon, Temecula, CA), mouse monoclonal anti-Cx45 Q14E(mab19-11-5) (Coppen et al. 2003) or mouse monoclonal anti-V5 (Invitrogen). After washing, immunoreactivity was detected using Cy3labeled secondary antibodies (donkey antimouse $\mathrm{IgG}$, Chemicon; swine anti-rabbit, Dako, Carpinteria, CA). Cells were rewashed and mounted with Citifluor mounting medium (Agar, Stansted, UK). Specificity of labeling was confirmed by the omission of primary antibody and by checking reactivity on cells expressing irrelevant Cxs. All were negative. Immunolabeling was examined by confocal laser scanning microscopy (Leica, Heidelberg, Germany; TCS 4D).
Electrophysiological Measurements

Electrical recordings were performed as previously described (Desplantez et al. 2004). Briefly, glass coverslips with adherent cells were transferred to a chamber placed on an inverted microscope (Diaphot-TMD; Nikon, Tokyo, Japan), cell pairs were chosen and the dual voltage-clamp method (EPC 9/2; Heka Elektronik, Lambrecht/Pfalz, Germany) in the whole-cell configuration was applied. This method enabled control of the membrane potential of each cell, $V_{1}$ and $V_{2}$, to establish transjunctional potentials, $V_{\mathrm{j}}=V_{2}-V_{1}$, and measure the gap junction currents, $-I_{\mathrm{j}}$. Experiments were performed at room temperature $\left(22-25^{\circ} \mathrm{C}\right)$ in modified Krebs-Ringer solution (in $\mathrm{mM}$ ): $\mathrm{NaCl}, 140 ; \mathrm{KCl}, 4 ; \mathrm{CaCl}_{2}, 2$; $\mathrm{MgCl}_{2}$, 1; HEPES, 5 (pH 7.4); sodium pyruvate, 2; glucose, 5. Immediately before use, patch pipettes were filled with internal solution (in $\mathrm{mM}$ ): potassium aspartate, $130 ; \mathrm{NaCl}$, 10; $\mathrm{CaCl}_{2}, 1$; MgATP, 3; EGTA, 10 (pCa 8); HEPES, 5 (pH 7.2). When filled with solution, patch pipettes had DC resistances of 2-5 $\mathrm{M} \Omega$.

Acquisition and Analysis of Electrophysiological Data

Voltage and current signals were stored on a PC for offline analysis. Current signals were Bessel-filtered $(1 \mathrm{kHz})$ and digitized $(3.33 \mathrm{kHz})$. Data acquisition and analysis were done with PULSE and PULSFIT software (Heka Elektronik); curve fitting and statistics were performed with SigmaPlot and SigmaStat, respectively (Jandel Scientific, Erkrath, Germany). For analysis, the amplitude of $I_{\mathrm{j}}$ was determined at the beginning, $I_{\mathrm{j} \text {,inst }}$ (inst, instantaneous), and end, $I_{\mathrm{j}, \text { ss }}$ (ss, steady state), of each $V_{\mathrm{j}}$ pulse. At large $V_{\mathrm{j}}, I_{\mathrm{j}, \text { inst }}$ was gained by extrapolation to time $t=0 \mathrm{~s}$ (onset of pulse). Conductances were calculated as $g_{\mathrm{j}, \text { inst }}=I_{\mathrm{j} \text {,inst }} / V_{\mathrm{j}}$ and $g_{\mathrm{j}, \mathrm{ss}}=$ $I_{\mathrm{j}, \mathrm{ss}} / V_{\mathrm{j}}$. Values of $g_{\mathrm{j}, \mathrm{ss}}$ were normalized with respect to $g_{\mathrm{j}, \text { inst }}$, sampled, averaged and plotted as $g_{\mathrm{j}, \mathrm{ss}}$ vs. $V_{\mathrm{j}}$. Curve fitting was done with the Boltzmann equation separately applied to negative and positive $V_{\mathrm{j}}$ data (Valiunas et al. 1999):

$g_{\mathrm{j}, \mathrm{ss}}=\frac{1-g_{\mathrm{j}, \min }}{1+e^{\left[A \cdot\left(V_{\mathrm{j}}-V_{\mathrm{j}, 0}\right)\right]}}+g_{\mathrm{j}, \min }$

The parameter $g_{\mathrm{j}, \min }$ is the normalized conductance at large $V_{\mathrm{j}}$, and $V_{\mathrm{j}, 0}$ corresponds to $V_{\mathrm{j}}$ at which $g_{\mathrm{j}, \mathrm{ss}} / g_{\mathrm{j} \text {,inst }}$ is halfmaximally deactivated. $A$ is a constant expressing gating charge, $z q(k T)^{-1}$, where $z$ is the equivalent number of unitary positive charges $(q)$ moving through the electric field applied and $k$ and $T$ are the Boltzmann constant and the temperature in Kelvin, respectively. In the case of asymmetrical behavior (see also electronic supplement), the $g_{\mathrm{j}, \mathrm{ss}} / g_{\mathrm{j}, \text { inst }}$ data were fitted to a modified equation which allowed simultaneous treatment of data for positive and negative $V_{\mathrm{j}}$ (Chen-Izu et al. 2001). To analyze the time course of $I_{\mathrm{j}}$ deactivation, the $I_{\mathrm{j}}$ signals were subjected to a least-square curve fitting. They 
were best described by single exponentials or the sum of two exponentials (Sakai et al. 2003):

$I_{\mathrm{j}}(t)=I_{\mathrm{j} 1, \text { inst }} e^{-\frac{\mathrm{t}}{\tau_{\mathrm{d} 1}}}+I_{\mathrm{j} 2, \text { inst }} e^{-\frac{\mathrm{t}}{\tau_{\mathrm{d} 2}}}+I_{\mathrm{j}, \mathrm{ss}}$

$I_{\mathrm{j} 1 \text {,inst }}$ and $I_{\mathrm{j} 2 \text {,inst }}$ are the amplitudes of $I_{\mathrm{j}}$ representing the contribution of the fast and slow components, respectively, prevailing at the beginning of a voltage pulse; $I_{\mathrm{j}, \mathrm{ss}}$ is the amplitude of $I_{\mathrm{j}}$ at the end of a voltage pulse; and $\tau_{\mathrm{d} 1}$ and $\tau_{\mathrm{d} 2}$ are the respective time constants of deactivation.

Poorly coupled cell pairs or normally coupled pairs partially uncoupled with heptanol $(3 \mathrm{mM})$ were used to study single-channel currents elicited at different $V_{\mathrm{j}}$ gradients of either polarity. Current records were analyzed to determine the amplitude of discrete current levels.

The data are presented as means \pm 1 SEM. Data were compared with Student's $t$-test, unpaired. $P \leq 0.05$ was considered significant.

\section{Results}

\section{Transfection and Transfectant Characterization}

Our original transfection using the pcDNA3.1 constructs generated clones that displayed a heterogeneous expression, with areas of the dish expressing very little Cx. Although resistant to hygromycin $\mathrm{B}$, no $\mathrm{Cx}$ expression could be detected in the majority of the clones. Using an internal ribosome entry site (IRES) to physically link $\mathrm{CX}$ and antibiotic resistance on the same mRNA (see Fig. 1), the majority of transfectants were positive for Cx expression and a homogeneous pattern of expression was obtained (see Fig. 2; see also Halliday et al. 2003). Cxs are detectable with anti-V5 antibodies and with their respective anti-Cx antibodies. However, cytoplasmic detectability representing cytoplasmic connexons was somewhat stronger with the V5 antibody. For Cx45, most of the signal was cytoplasmic and little was found in the form of gap junctions. Nevertheless, typical punctate labeling at cell contacts representing gap junctions was detectable with all antibodies (see Fig. 2).

Since the Cxs are tagged with the same epitope (V5), Cx levels can be compared. The Western blot experiments in Fig. 3 show that the levels of expression in the transfectants followed the sequence $\mathrm{Cx} 43>\mathrm{Cx} 45>\mathrm{Cx} 40$ but the differences were not large. Detection with the specific anti$\mathrm{Cx}$ antibodies shows identical results in terms of banding pattern and molecular weight (data not shown).

Voltage Dependence of $g_{\mathrm{j}}$

Figure 4a, upper panel, shows records of junctional currents, $I_{\mathrm{j}}$, of a cell pair expressing His-tagged rat $\mathrm{Cx} 43$
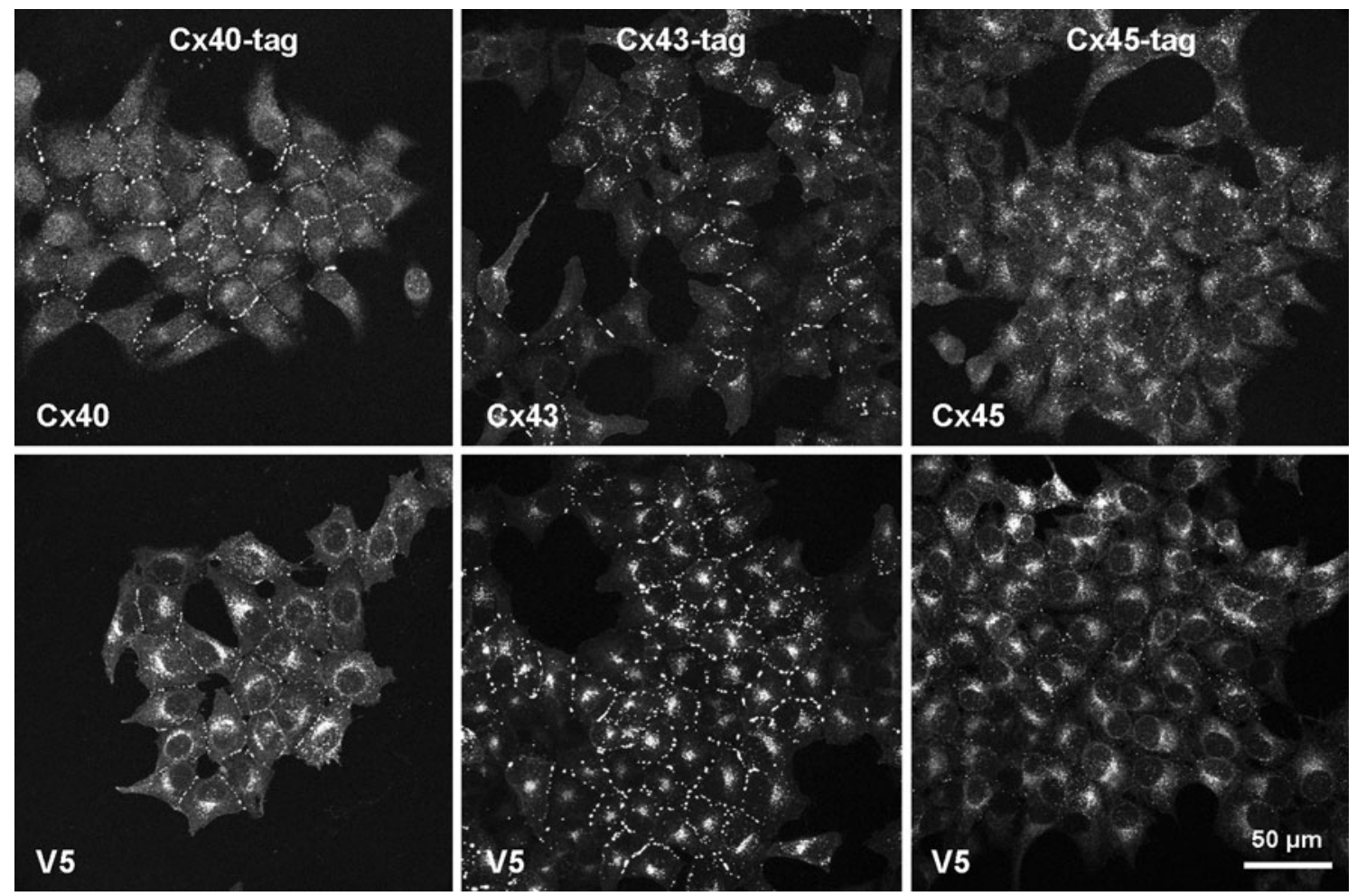

Fig. 2 Characterization of transfectants by immunofluorescence. Upper images Staining with specific anti-Cx antibody. Lower images Staining with anti-V5 antibody. Note the strong intracellular labeling, particularly when using anti-V5 antibody. Cx45 junctional labeling is always present but dim 


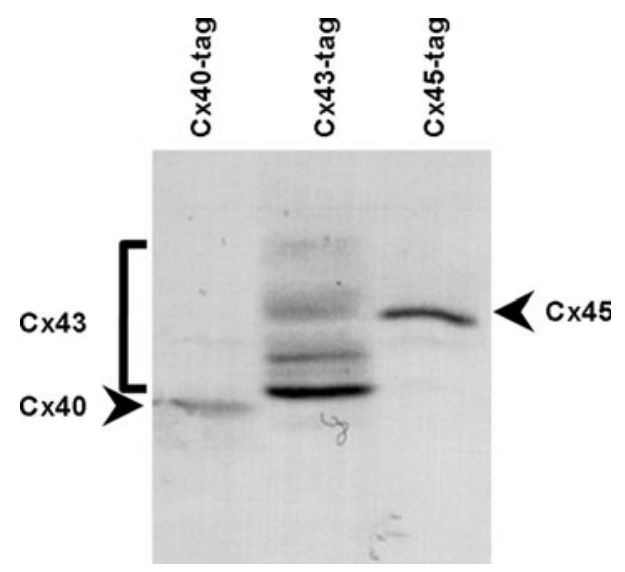

Fig. 3 Characterization of transfectants by Western blotting. Migration was from top to bottom. Names of the clonal lines are indicated at the top. The different tagged connexins were detected using the same anti-V5 antibody. The migration of each connexin is indicated. Comparison of expression levels is possible because of the presence of the same epitope on the three different molecules. Although comparable, the level of expression is higher for $\mathrm{Cx} 43$, lower for $\mathrm{Cx} 40$ and intermediate for $\mathrm{Cx} 45$. Note that the tagged $\mathrm{Cx} 43$ migrates with the classical multiband pattern caused by various levels of phosphorylation
(Cx43-tag). Signals were evoked by pulsing cell 1 to establish a transjunctional voltage, $V_{\mathrm{j}}$, of $\pm 10, \pm 40, \pm 70$, \pm 100 and $\pm 130 \mathrm{mV}$. Depolarization of cell 1 provoked a negative $V_{\mathrm{j}}$ and led to an inward $I_{\mathrm{j}}$ (downward deflection) and vice versa (see Electrophysiological Measurements). The currents were symmetrical with regard to $V_{\mathrm{j}}$ polarity. Figure $4 \mathrm{a}$, lower panel, summarizes the results of homotypic Cx43-tag channels plotting the normalized conductance at steady state, $g_{\mathrm{j}, \mathrm{ss}} / g_{\mathrm{j} \text {,inst }}$, vs. $V_{\mathrm{j}}(\mathbf{)})$. The data follow a symmetrical sigmoidal relationship. The solid curve represents the best fit of data to Eq. 1. The dashed curve shows the function $g_{\mathrm{j}, \mathrm{ss}} / g_{\mathrm{j}, \text { inst }}=f\left(V_{\mathrm{j}}\right)$ for homotypic wt-43 channels (data points omitted for clarity; replotted from Desplantez et al. 2004). The Boltzmann parameters of Cx43-tag and wt-Cx43 channels are given in Table 1. Data comparison indicates that $g_{\mathrm{j}, \mathrm{ss}}$ of the Cx43-tag is less voltage-sensitive. When extrapolated to $V_{\mathrm{j}}=0 \mathrm{mV}$, the average maximal conductance, $G_{\mathrm{j}, \text { inst }}$, of the Cx43-tag was $3.0 \pm 0.26 \mathrm{nS}(n=10)$. Hence, it is 2.7 -fold smaller than that of wt-Cx43, i.e., $8.0 \pm 1.6 \mathrm{nS}(n=11$, taken from Desplantez et al. 2004), $P<0.025$.
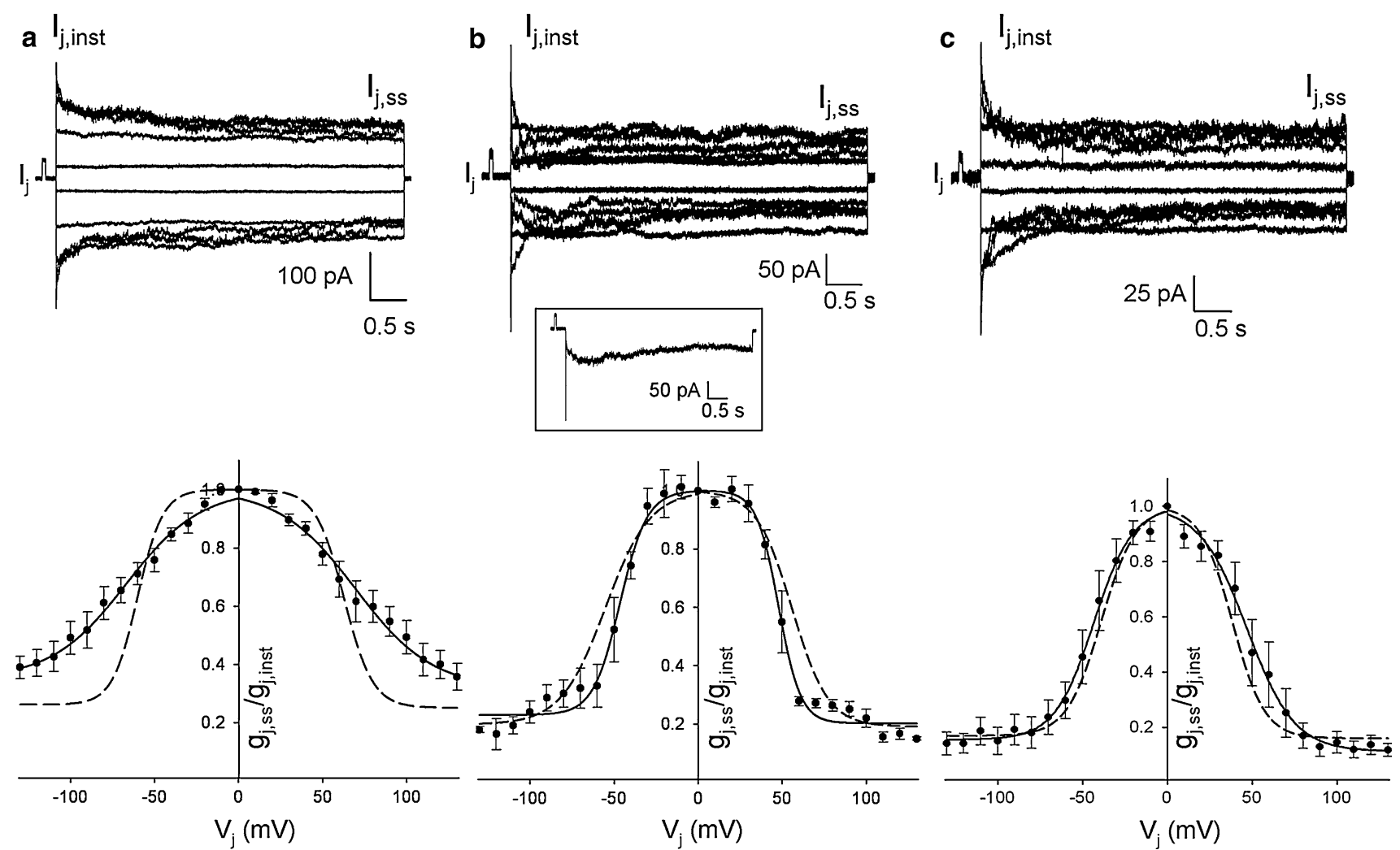

Fig. 4 Homotypic cell pairs: voltage dependence of $g_{\mathrm{j}}$. Data of $\mathrm{Cx} 43-$ tag (a), Cx40-tag (b) and $\mathrm{Cx} 45$-tag (c) cell pairs. Upper panels Superimposed current records, $I_{\mathrm{j}}$. Currents elicited at $V_{\mathrm{j}}= \pm 10, \pm 40$, $\pm 70, \pm 100$ and $\pm 130 \mathrm{mV}$. Note different vertical scales. Inset in b Example of a complex $I_{\mathrm{j}}$ signal at $V_{\mathrm{j}}=-130 \mathrm{mV}$. Lower panels Respective plots of normalized conductance at steady-state, $g_{\mathrm{j}, \mathrm{ss}} / g_{\mathrm{j}, \text { inst }}$ vs. $V_{\mathrm{j}}(\mathbf{O})$. Solid curve Best fit of data to the Boltzmann equation for tagged channels. Dashed curve Best fit for wild-type channels (wtCx43, wt-Cx45 from Desplantez et al. [2004]; wt-Cx40 from Desplantez et al. [2007]; data points omitted for clarity). For analysis, see text; for data, see Table 1 
Table 1 Boltzmann parameters

\begin{tabular}{llll}
\hline Preparation & $V_{\mathrm{j}, 0}(\mathrm{mV})$ & $g_{\mathrm{j}, \min }$ & $z$ \\
\hline Cx43-tag/Cx43-tag & $-67.0 / 69.7(2.5 / 3.3)$ & $0.35 / 0.32(0.02 / 0.03)$ & $-1.15 / 1.12(0.09 / 0.10)$ \\
wt-Cx43/wt-Cx43 ${ }^{\mathrm{a}}$ & $-60.8 / 62.9(0.6 / 0.4)$ & $0.26 / 0.25(0.01 / 0.01)$ & $-3.4 / 2.9(0.23 / 0.13)$ \\
wt-Cx43/Cx43-tag & $-72.5 / 70.9(2.9 / 2.1)$ & $0.23 / 0.30(0.02 / 0.02)$ & $-1.3 / 2.1(0.07 / 0.16)$ \\
Cx40-tag/Cx40-tag & $-46.5 / 47.5(1.3 / 1.3)$ & $0.24 / 0.20(0.02 / 0.02)$ & $-3.3 / 3.8(0.51 / 0.48)$ \\
wt-Cx40/wt-Cx40 & $-55.1 / 55.9(1.6 / 1.1)$ & $0.20 / 0.19(0.02 / 0.01)$ & $-1.82 / 2.3(0.18 / 0.20)$ \\
wt-Cx40/Cx40-tag & $-124.5 / 10.2(11.3 / 2.1)$ & n.d./0.07(-/0.01) & $-0.33 / 1.8(0.01 / 0.18)$ \\
Cx45-tag/Cx45-tag & $-43.4 / 47.0(0.8 / 1.2)$ & $0.15 / 0.12(0.01 / 0.02)$ & $-2.2 / 1.8(0.13 / 0.13)$ \\
wt-Cx45/wt-Cx45 & $-38.9 / 38.5(0.7 / 0.7)$ & $0.17 / 0.16(0.01 / 0.01)$ & $-2.5 / 2.7(0.18 / 0.17)$ \\
wt-Cx45/Cx45-tag & $-71.9 / 17.4(1.9 / 2.5)$ & n.d./0.18(-/0.02) & $-2.04 / 1.61(0.26 / 0.20)$ \\
\hline
\end{tabular}

Means \pm 1 SEM (in parentheses)

a Data taken from Desplantez et al. (2004)

${ }^{\mathrm{b}}$ Data taken from Desplantez et al. (2007). For experiments on mixed channels, see electronic supplement

$V_{\mathrm{j}, 0}, V_{\mathrm{j}}$ at which $g_{\mathrm{j}, \mathrm{ss}}$ is half-maximally inactivated; $g_{\mathrm{j}, \mathrm{min}}$, minimal conductance at large $V_{\mathrm{j}}$; $z$, equivalent number of unitary positive charges $q$ moving through the electric field applied; $n$, number of cell pairs; n.d., not determined

$P$ values $\left(V_{\mathrm{j}, 0}, g_{\mathrm{j}, \min }, z\right):<0.05,<0.05,<0.0001$ (homotypic $\mathrm{Cx} 43$ ); $<0.0001,>0.05,<0.05$ (homotypic $\mathrm{Cx} 40$ ); $<0.0001,>0.05,<0.05$ (homotypic $\mathrm{Cx} 45$ )

Figure $4 \mathrm{~b}$, upper panel, shows $I_{\mathrm{j}}$ records of a cell pair expressing the Cx40-tag. The currents were symmetrical with respect to $V_{\mathrm{j}}$ polarity. In contrast to wt-Cx40 channels (Desplantez et al. 2007), currents carried by Cx40-tag channels failed to decay exponentially at $\left|V_{\mathrm{j}}\right|>100 \mathrm{mV}$. Instead, $I_{\mathrm{j}}$ showed a complex response consisting of a large initial spike, followed by a small component with a transient increase (see inset). Figure 4b, lower panel, summarizes the results for both types of cell pairs, showing plots of the normalized function $g_{\mathrm{j}, \mathrm{ss}} / g_{\mathrm{j}, \text { inst }}=f\left(V_{\mathrm{j}}\right)$. The data of Cx40-tag (, solid curve) and wt-Cx40 channels (dashed curve, data points omitted for clarity; replotted from Desplantez et al. 2007) exhibited a symmetrical sigmoidal relationship. The curves represent the best fit of data to Eq. 1 (for Boltzmann parameters, see Table 1). Data comparison indicates that $g_{\mathrm{j}, \mathrm{ss}}$ of $\mathrm{Cx} 40$-tag is slightly more sensitive to $V_{\mathrm{j}}$. The average $G_{\mathrm{j} \text {,inst }}$ of the Cx40-tag extrapolated to $V_{\mathrm{j}}=0 \mathrm{mV}$ was $2.5 \pm 0.5 \mathrm{nS}(n=4)$, i.e., 2.5-fold smaller than that of $\mathrm{w}-\mathrm{Cx} 40,6.3 \pm 0.9 \mathrm{nS}(n=13$, taken from Desplantez et al. 2007), $P>0.05$.

Figure 4c, upper panel, shows $I_{\mathrm{j}}$ records of a cell pair expressing the Cx45-tag. Figure 4c, lower panel, summarizes the results for both types of cell pairs plotting $g_{\mathrm{j}, \mathrm{ss}} /$ $g_{\mathrm{j}, \text { inst }}=f\left(V_{\mathrm{j}}\right)$. In the case of the Cx45-tag ( $\mathbf{O}$, solid curve) and wt-Cx45 (dashed curve, data points omitted for clarity; replotted from Desplantez et al. 2004), the data described a symmetrical bell-shaped relationship. Curves correspond to the best fit of data to Eq. 1 (for Boltzmann parameters, see Table 1). Data comparison reveals that $g_{\mathrm{j}, \mathrm{ss}}$ of the Cx45-tag is slightly less sensitive to $V_{\mathrm{j}}$. The average $G_{\mathrm{j}, \text { inst }}$ of the Cx45-tag extrapolated to $V_{\mathrm{j}}=0 \mathrm{mV}$ was $0.9 \pm 0.1 \mathrm{nS}(n=$ 5), i.e. 6.7-fold smaller that that of wt-Cx45, $6.0 \pm 0.5 \mathrm{nS}$ ( $n=13$, taken from Desplantez et al. 2004), $P<0.005$. Another series of experiments explored the multichannel properties of heterotypic wt-Cx/Cx-tag cell pairs (see electronic supplement).
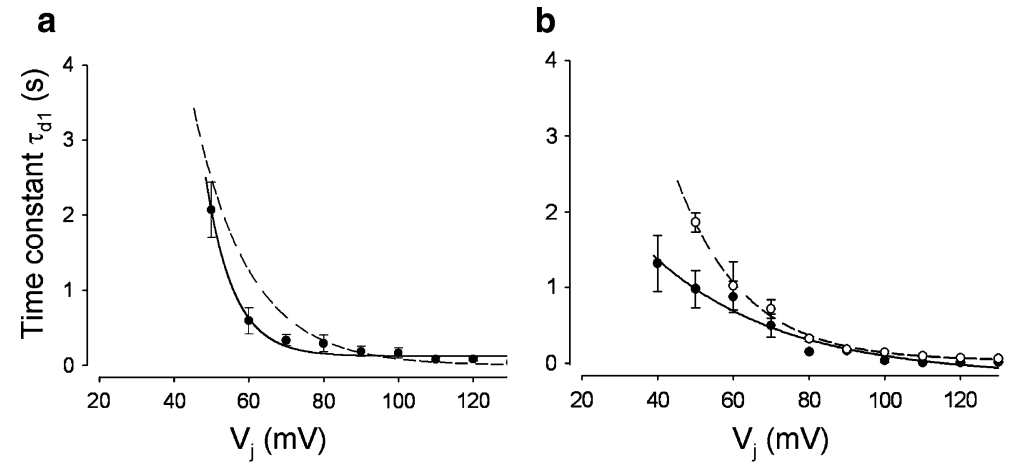

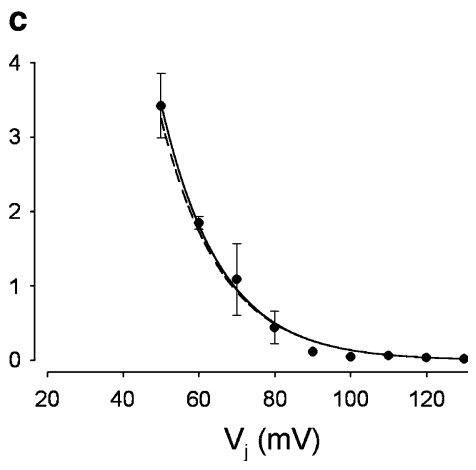

Fig. 5 Kinetics of $I_{\mathrm{j}}$ deactivation. Plot of time constants of $I_{\mathrm{j}}$ deactivation of fast component, $\tau_{\mathrm{d} 1}$, vs. $V_{\mathrm{j}}$. Data of $\mathrm{Cx} 43$ (a), $\mathrm{Cx} 40$ (b) and $\mathrm{Cx} 45$ (c). Solid curve and Best fit of data to an exponential for tagged channels. Dashed curve and $\bigcirc$ Best fit for wild-type channels (wt-Cx43 and wt-Cx45 reproduced from Desplantez et al. 2004, data points omitted). For analysis, see text; for data, see Table 2 
Kinetics of $I_{\mathrm{j}}$ Deactivation

In homotypic Cx43-tag and wt-Cx43 channels, $I_{\mathrm{j}}$ decreased with time monoexponentially at smaller $V_{\mathrm{j}}$ and biexponentially at larger $V_{\mathrm{j}}$, giving rise to one or two time constants of deactivation, i.e., $\tau_{\mathrm{d} 1}$ or $\tau_{\mathrm{d} 1}$ and $\tau_{\mathrm{d} 2}$ (see Eq. 2 ); $\tau_{\mathrm{d} 2}$ was apparent at $\left|V_{\mathrm{j}}\right| \geq 80$ and $90 \mathrm{mV}$, respectively (data not shown). Since $\tau_{\mathrm{d} 1}$ predominantly determines the decay of $I_{\mathrm{j}}$ and $\tau_{\mathrm{d} 2}$ was difficult to assess due to signal size, the former was used for further analysis. Reliable $\tau_{\mathrm{d} 1}$ data were obtained at $\left|V_{\mathrm{j}}\right|$ $\geq 50 \mathrm{mV}$. At smaller voltages, the analysis was hampered by slow decays and poor signal-to-noise ratios. Figure 5a summarizes the results of the analysis plotting the function $\tau_{\mathrm{d} 1}=$ $f\left(V_{\mathrm{j}}\right)$ for Cx43-tag (O, solid curve) and wt-Cx43 (dashed curve, data points omitted for clarity; replotted from Desplantez et al. 2004). Values for negative and positive $V_{\mathrm{j}}$ were pooled for reasons of symmetry. Curves represent the best fit of data to a single exponential (for parameters, see Table 2). They indicate that tagging decreased $\tau_{\mathrm{d} 1}$ at $50 \mathrm{mV}<\left|V_{\mathrm{j}}\right|<$ $100 \mathrm{mV}$ and increased it at $50 \mathrm{mV}>\left|V_{\mathrm{j}}\right|>100 \mathrm{mV}$, hence accelerating and decelerating $I_{\mathrm{j}}$ deactivation, respectively.

In Cx40-tag channels, $I_{\mathrm{j}}$ decreased with time monoexponentially at $\left|V_{\mathrm{j}}\right| \leq 100 \mathrm{mV}$, giving rise to $\tau_{\mathrm{d} 1}$ (not shown); at $\left|V_{\mathrm{j}}\right|>100 \mathrm{mV}, I_{\mathrm{j}}$ showed a rapid decay followed by a slow transient increase, thus preventing further analysis (see Fig. $4 \mathrm{~b}$, inset). In wt-Cx40 channels, $I_{\mathrm{j}}$ decreased monoexponentially at smaller $V_{\mathrm{j}}$ and biexponentially at larger $V_{\mathrm{j}}$, giving rise to $\tau_{\mathrm{d} 1}$ or $\tau_{\mathrm{d} 1}$ and $\tau_{\mathrm{d} 2}$, respectively; $\tau_{\mathrm{d} 2}$ was visible at $\left|V_{\mathrm{j}}\right| \geq 100 \mathrm{mV}$ (not shown). Figure $5 \mathrm{~b}$ summarizes the results of the analysis plotting $\tau_{\mathrm{d} 1}=f\left(V_{\mathrm{j}}\right)$ for Cx40-tag ( solid curve) and wt-Cx40 ( $\bigcirc$, dashed curve). Values for negative and positive $V_{\mathrm{j}}$ were pooled. Smooth curves represent the best fit of data to an exponential (for parameters, see Table 2). Curves indicate that tagging decreased $\tau_{\mathrm{d} 1}$ at each $\left|V_{\mathrm{j}}\right|$ examined, thus accelerating $I_{\mathrm{j}}$ deactivation throughout.

Table 2 Kinetics of fast component of $I_{\mathrm{j}}$ deactivation

\begin{tabular}{llcr}
\hline Preparation & $V_{\tau}(\mathrm{mV})$ & $\tau_{\mathrm{d}, 0}(\mathrm{~s})$ & $n$ \\
\hline Cx43-tag/Cx43-tag & $10.1 \pm 1.8$ & $280 \pm 14.5$ & 15 \\
wt-Cx43/wt-Cx43 $^{\mathrm{a}}$ & $14.8 \pm 0.8$ & $72.2 \pm 13.4$ & 11 \\
Cx40-tag/Cx40-tag & $25.6 \pm 1.9$ & $6.6 \pm 1.8$ & 8 \\
wt-Cx40/wt-Cx40 & $18.5 \pm 1.4$ & $26.5 \pm 6.3$ & 13 \\
Cx45-tag/Cx45-tag & $15.9 \pm 0.6$ & $86.2 \pm 13.9$ & 9 \\
wt-Cx45/wt-Cx45 $^{\mathrm{a}}$ & $13.5 \pm 1.1$ & $132.3 \pm 44.5$ & 15 \\
\hline
\end{tabular}

Means \pm 1 SEM. Data gained at negative and positive $V_{\mathrm{j}}$ were pooled

${ }^{a}$ Data taken from Desplantez et al. (2004)

$V_{\tau}$, decay constant, i.e., characteristic measure for the decay of $\tau_{\mathrm{d} 1}$ with $V_{\mathrm{j}} ; \tau_{\mathrm{d}, 0}$, zero $V_{\mathrm{j}}$ intercept, i.e., value of $\tau_{\mathrm{d} 1}$ extrapolated to $V_{\mathrm{j}}=$ $0 \mathrm{mV} ; n$, number of cell pairs

$P$ values $\left(V_{\tau}, \tau_{\mathrm{d}, 0}\right):<0.0001,<0.0001(\mathrm{Cx} 43) ;>0.05,<0.05(\mathrm{Cx} 40)$; $>0.05,>0.05(\mathrm{Cx} 45)$
Table 3 Contribution of fast and slow components of $I_{\mathrm{j}}$ deactivation

\begin{tabular}{lllr}
\hline Preparation & $I_{\mathrm{j} 1 \text {,inst }}(\%)$ & $I_{\mathrm{j} 2 \text {,inst }}(\%)$ & $n$ \\
\hline Cx43-tag/Cx43-tag & $36.2 \pm 3.7$ & $63.8 \pm 5.6$ & 15 \\
wt-Cx43/wt-Cx43 & $80.0 \pm 3.8$ & $20.0 \pm 3.8$ & 7 \\
Cx40-tag/Cx40-tag & $62.1 \pm 7.1$ & $37.9 \pm 7.1$ & 7 \\
wt-Cx40/wt-Cx40 & $78.8 \pm 4.9$ & $21.2 \pm 4.9$ & 8 \\
Cx45-tag/Cx45-tag & $66.2 \pm 1.7$ & $33.8 \pm 5.9$ & 9 \\
wt-Cx45/wt-Cx45 & $86.3 \pm 0.8$ & $13.7 \pm 0.8$ & 15
\end{tabular}

Means \pm 1 SEM. Values of $I_{\mathrm{j} 1 \text {,inst }}$ and $I_{\mathrm{j} 2 \text {,inst }}$ were determined at $t=0$ using $I_{\mathrm{j}}$ records obtained at $V_{\mathrm{j}}=110 \mathrm{mV}$

$I_{\mathrm{i} 1 \text {,inst }}, I_{\mathrm{i} 2 \text {,inst }}$, relative amplitudes of $I_{\mathrm{j}}$ of the fast and slow components, respectively; $n$, number of cell pairs

$P$ values $\left(I_{\mathrm{j} 1 \text {,inst }}, I_{\mathrm{j} 2 \text {,inst }}\right):<0.0001,<0.0001(\mathrm{Cx} 43) ;>0.05,>0.05$ (Cx40); <0.0001, <0.0001 (Cx45)

In Cx45-tag and wt-Cx45 channels, $I_{\mathrm{j}}$ decreased monoexponentially at smaller $V_{\mathrm{j}}$ and biexponentially at larger $V_{\mathrm{j}}$ furnishing $\tau_{\mathrm{d} 1}$ or $\tau_{\mathrm{d} 1}$ and $\tau_{\mathrm{d} 2} ; \tau_{\mathrm{d} 2}$ was apparent at $\left|V_{\mathrm{j}}\right| \geq$ 80 and $90 \mathrm{mV}$, respectively (not shown). Figure $5 \mathrm{c}$ summarizes the results of the analysis plotting $\tau_{\mathrm{d} 1}=f\left(V_{\mathrm{j}}\right)$ for Cx45-tag (, solid curve) and wt-Cx45 (dashed curve, data points omitted; replotted from Desplantez et al. 2004). Again, values for negative and positive $V_{\mathrm{j}}$ were pooled. Smooth curves represent the best fit of data to an exponential (for parameters, see Table 2). Curves reveal that tagging had no effect on $\tau_{\mathrm{d} 1}$.

$I_{\mathrm{j}}$ deactivation of channels made of tagged or wild-type Cxs proceeds biexponentially at larger $V_{\mathrm{j}} \mathrm{s}$, suggesting the operation of fast and slow components, $I_{\mathrm{j} 1}$ and $I_{\mathrm{j} 2}$ (see Eq. 2). Hence, kinetic analyses furnish not only time constants, i.e., $\tau_{\mathrm{d} 1}$ and $\tau_{\mathrm{d} 2}$ (see above), but also values for the relative contribution of both components, i.e., $I_{\mathrm{j} 1 \text {,inst }}$ and $I_{\mathrm{j} 2 \text {,inst }}$, corresponding to their fractional amplitudes of $I_{\mathrm{j}}$ at time $t=0$. The mean values obtained for $I_{\mathrm{j} 1 \text {,inst }}$ and $I_{\mathrm{j} 2 \text {,inst }}$ determined at $V_{\mathrm{j}}=110 \mathrm{mV}$ are given in Table 3 . Comparison of the data indicates that tagging lowered $I_{\mathrm{j} 1 \text {,inst }}$ and increased $I_{\mathrm{j} 2 \text {,inst }}$, irrespective of the type of $\mathrm{Cx}$, implying a shift from the fast to the slow component.

\section{Unitary Conductances}

Cell pairs poorly coupled or partially uncoupled by exposure to $3 \mathrm{mM}$ heptanol were used to examine singlechannel currents. Figure 6, left panels, shows records of a homotypic Cx43-tag (Fig. 6a), Cx40-tag (Fig. 6b) and Cx45-tag cell pair (Fig. 6c). For comparison, Fig. 6, right panels, shows records of a homotypic wt-Cx43 (Fig. 6a), wt-Cx40 (Fig. 6b) and wt-Cx45 cell pairs (Fig. 6c). Currents were elicited with a symmetrical bipolar pulse protocol, establishing a positive and negative $V_{\mathrm{j}}$. In each case, $I_{\mathrm{j}}$ revealed two prominent levels, attributable to the channel main open state (dashed line) and residual open state 
Fig. 6 Homotypic cell pairs: single-channel conductance. Data of cell pairs with tagged Cxs (left) and wild-type Cxs (right). Upper panels Pulse protocol $\left(V_{1}, V_{2}\right)$ and current signal, $I_{\mathrm{j}}$. Solid line Zero current level. Pointed line Channel residual state. Dashed line Channel main state. Lower panels Frequency histogram of channel conductances. Curves reflect best fit of data to the sum of two gaussians; peaks to the left and right correspond to the mean conductance of the residual state, $\gamma_{\mathrm{j} \text {,residual, and }}$ main state, $\gamma_{\mathrm{j} \text {,main }}$, respectively. a Cx43 channels, bin width 5 pS. b Cx40 channels, bin width 5 pS. c Cx45 channels, bin width $2 \mathrm{pS}$ (smaller values require a narrower bin width)
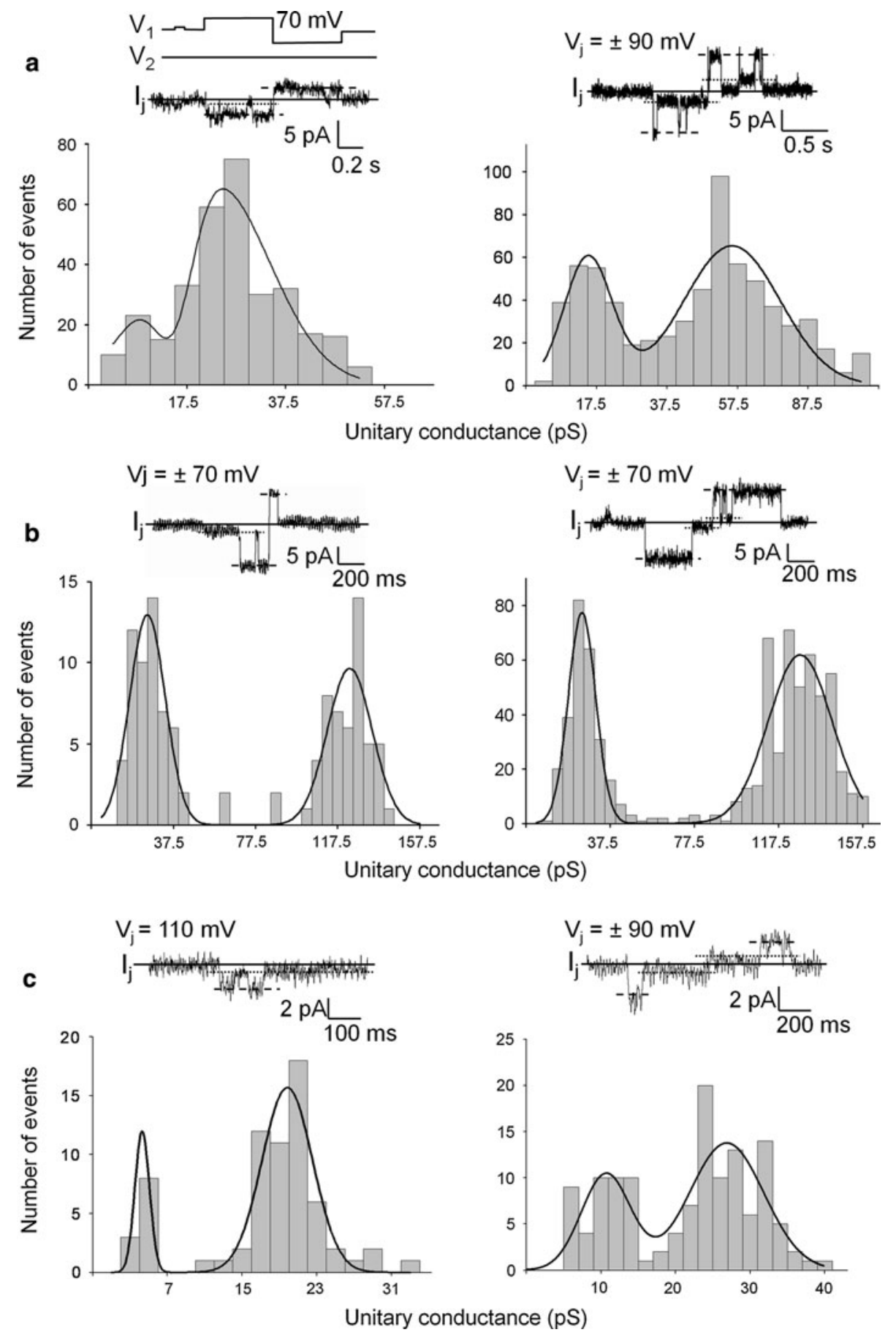

(pointed line). A closed state was observed occasionally (see Fig. 6a, left and right panels). The solid line refers to zero current. Channel conductances gained from such records were sampled, averaged and plotted as frequency histograms (Fig. 6a-c). Smooth curves represent the best fit of data to the sum of two gaussians. The left- and righthand distributions correspond to the conductance of the

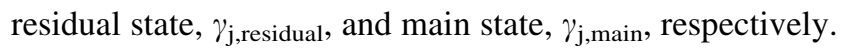
The means \pm 1 SEM derived from the peaks are given in Table 4. The data indicate that tagging decreases the channel conductance of $\mathrm{Cx} 43$ and $\mathrm{Cx} 45$ but not of $\mathrm{Cx} 40$. Using the same experimental approach, we also examined the single-channel properties of heterotypic wt-Cx/Cx-tag cell pairs (see electronic supplement).

\section{Discussion}

This study shows that fusion of a V5/6-His tag (hexa moiety $M_{\mathrm{r}}=0.93 \mathrm{kDa}$ ) to the CT segment of $\mathrm{Cx} 40, \mathrm{Cx} 43$ 
and $\mathrm{Cx} 45$ does not prevent the cells from forming channels. The tag contains 31 residues, including a 14-residue epitope readily detectable by a sensitive anti-V5 antibody and a stretch of histidines to facilitate purification with $\mathrm{Ni}^{2+}$ chelating resins. Immunoblot experiments indicate that expression is highest in $\mathrm{Cx} 43$ and lowest in $\mathrm{Cx} 40$ transfectants. Immunoconfocal experiments reveal that all constructs are detectable by both the Cx-specific and the anti-V5 antibodies as spots at cellular interfaces that represent GJCs. However, a sizable amount of intracellular immunoreactivity is also seen in the vicinity of the Golgi apparatus, particularly when using anti-V5 antibody. This phenomenon is less prominent in wt-Cxs (not shown), indicating that the tag interferes with trafficking but does not prevent protein folding, $\mathrm{HC}$ assembly and trafficking or $\mathrm{HC}$ insertion and docking. The final extremity of the CT of Cx43 (and probably of $\mathrm{Cx} 40$ and Cx45) contains a PDZbinding domain, and C-terminal tagging has been shown to interfere with ZO-1 binding (Toyofuku et al. 1998; Hunter et al. 2005; Giepmans and Moolenaar 1998; Laing et al. 2001). Loss of interaction with PDZ-containing proteins such as ZO-1 appears to interfere with trafficking. Interestingly, our anti-Cx40 antibody S15C(R83) does not bind to the cytoplasmic pool of Cx40-tag (although anti-V5 antibody binds to it), suggesting that residues 256-270 are not accessible to antibody binding during trafficking in the trans-Golgi network.

Our electrophysiological experiments demonstrate that V5/6-His tagged Cxs do form functional GJCs. Tagging provokes subtle changes at the multichannel and singlechannel levels. The effects are Cx-dependent.

\section{Electrophysiological and Biochemical Data}

Making use of the mean values of multichannel conductance, $G_{\mathrm{j}, \text { inst }}$ (see Voltage Dependence of $g_{\mathrm{j}}$ ), and singlechannel conductance, $\gamma_{\mathrm{j} \text {,main }}$ (see Table 4), we estimated the average number of functional channels as the ratio $A=$ $G_{\mathrm{j}, \text { inst }} / \gamma_{\mathrm{j} \text {,main }}$. The numbers obtained were 20,104 and 43 for homotypic Cx40-tag, $\mathrm{Cx} 43$-tag and $\mathrm{Cx} 45$-tag channels, respectively, which roughly match the expression levels observed by Western blotting using the anti-V5 antibody. Likewise, the estimated numbers of functional channels for the homotypic wt-Cx40, wt-Cx43 and wt-Cx45 channels were 49,137 and 223 , respectively.

The ratios $A=G_{\mathrm{j}, \text { inst }} / \gamma_{\mathrm{j} \text {,main }}$ deduced from studies on mixed wt-Cx/Cx-tag cell pairs $\left(G_{\mathrm{j}, \text { inst }}\right.$ data, see electronic supplement; $\gamma_{\mathrm{j} \text {,main }}$ data, see Table 4 ) have also been used to estimate the number of functional heterotypic channels. The values were 4 for $\mathrm{Cx} 40,84$ for $\mathrm{Cx} 43$ and 160 for $\mathrm{Cx} 45$. This indicates that the tag prevents proper docking and/or opening for $\mathrm{Cx} 40$ since each cell line has a much larger capacity for channel formation/opening. This is reminiscent
Table 4 Single-channel conductances

\begin{tabular}{lrrrl}
\hline Preparation & \multicolumn{1}{c}{$\gamma_{\mathrm{j}, \text { main }}(\mathrm{pS})$} & \multicolumn{1}{c}{$\gamma_{\mathrm{j}, \text { residual }}(\mathrm{pS})$} & \multicolumn{1}{l}{$N / n$} & \multicolumn{1}{l}{$r^{2}$} \\
\hline Cx43-tag/Cx43-tag & $28.9 \pm 1.6$ & $7.9 \pm 0.9$ & $316 / 12$ & 0.83 \\
wt-Cx43/wt-Cx43 & $58.4 \pm 1.8$ & $17.6 \pm 1.4$ & $646 / 14$ & 0.86 \\
wt-Cx43/Cx43-tag & $37.9 \pm 1.8$ & $13.5 \pm 1.4$ & $612 / 13$ & 0.97 \\
Cx40-tag/Cx40-tag & $126 \pm 1.5$ & $27.4 \pm 1.0$ & $110 / 6$ & 0.94 \\
wt-Cx40/wt-Cx40 & $130 \pm 1.5$ & $26.6 \pm 0.8$ & $732 / 5$ & 0.87 \\
wt-Cx40/Cx40-tag & $132.5 \pm 1.6$ & $30.5 \pm 1.2$ & $83 / 3$ & 0.85 \\
Cx45-tag/Cx45-tag & $20.8 \pm 0.3$ & $5.3 \pm 2.0$ & $70 / 2$ & 0.93 \\
wt-Cx45/wt-Cx45 & $26.9 \pm 1.0$ & $10.7 \pm 1.0$ & $129 / 3$ & 0.65 \\
wt-Cx45/Cx45-tag & $21.3 \pm 0.5$ & $10.5 \pm 1.0$ & $89 / 3$ & 0.94 \\
\hline
\end{tabular}

Means \pm 1 SEM. For experiments on mixed channels, see electronic supplement

$\gamma_{\mathrm{j}, \text { main }}$, conductance of main state; $\gamma_{\mathrm{j}, \text { residual }}$, conductance of residual state; $N / n$, number of observations/number of cell pairs; $r^{2}$, correlation coefficient

$P$ values $\left(\gamma_{\mathrm{j} \text {,main }}\right.$ and $\left.\gamma_{\mathrm{j}, \text { residual }}\right):<0.0001$ (homotypic $\mathrm{Cx} 43$ ); $>0.05$ (homotypic Cx40); <0.0001 (homotypic Cx45)

of the observation that exchanging Cx40 CT for Cx43 CT leads to low channel formation (Haubrich et al. 1996). For $\mathrm{Cx} 43$, the reduction of the number of channels is less prominent but may be due to similar causes. However, wildtype $\mathrm{Cx} 45$ seems to rescue the poor coupling obtained with tagged $\mathrm{Cx} 45$ to a level similar to the wild-type molecule, indicating that tagged $\mathrm{Cx} 45$ has a much larger capacity for communication. These observations indicate a strong influence of the $\mathrm{CT}$ in channel formation/opening.

Immunofluorescence experiments indicate the detectability of gap junctions to be $\mathrm{Cx} 45<\mathrm{Cx} 40 \leq \mathrm{Cx} 43$ for both tagged and wild-type Cxs, suggesting that the number of open channels correlates poorly with levels of expression or number and size of gap junctions and thus indicates a specific regulation for each $\mathrm{Cx}$ in HeLa cells. This confirms previous findings that only a small fraction of channels are functional (Bukauskas et al. 2000).

\section{Electrical Properties of Cx43-Tag Channels}

Among the Cxs examined, tagging of $\mathrm{Cx} 43$ most prominently alters the properties of multichannel and singlechannel currents. These findings have to be discussed in the context of the current concept of GJC operation, which proposes two $V_{\mathrm{j}}$-sensitive gates acting separately in each HC, a fast gate characterized by fast current transitions between the main state and residual state and a slow gate allocated by slow current transitions between the main state and closed state (Bukauskas and Verselis 2004). At the multichannel level, these gates enable fast and slow components of $I_{\mathrm{j}}$ deactivation as reflected by a biexponential process. This concept relies on the following results. Fusion of EGFP $\left(\mathrm{M}_{\mathrm{r}} \approx 28 \mathrm{kDa}\right)$ to CT of $\mathrm{Cx} 43$ impairs the 
$V_{\mathrm{j}}$ sensitivity of $I_{\mathrm{j}}$, decreases $g_{\mathrm{j}, \min }$ at large $V_{\mathrm{j}}$ and elimi-

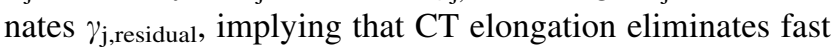
$V_{\mathrm{j}}$ gating (Bukauskas et al. 2001). However, CT truncation of $\mathrm{Cx} 43$ provokes similar effects, a decrease in $V_{\mathrm{j}}$ sensitivity of $I_{\mathrm{j}}$ and $g_{\mathrm{j}, \min }$, loss of the fast component of $I_{\mathrm{j}}$ deactivation and $\gamma_{\mathrm{j} \text {,residual }}$ and prolongation of $P_{\mathrm{o}}$ (Revilla et al. 1999; Moreno et al. 2002). This suggests that the CT is an effecter of fast $V_{\mathrm{j}}$ gating, likely to interact with a receptor at the pore-forming region involving the NT and/ or CL domain (Bukauskas et al. 2001; Shibayama et al. 2006). Hence, a change in CT length modifies or eliminates inherent properties of GJCs.

Our experiments reveal that V5/6-His tagging of $\mathrm{Cx} 43$ $\left(M_{\mathrm{r}}=0.93 \mathrm{kDa}\right)$ evokes changes in channel properties resembling those described above but less developed. It prominently reduces the $V_{\mathrm{j}}$ sensitivity of $I_{\mathrm{j}}$, as indicated by a larger $V_{\mathrm{j}, 0}$ and smaller $z$, and increases the residual conductance at large $V_{\mathrm{j}}$, as reflected by a rise in $g_{\mathrm{j}, \min }$ (see Table 1). The reduced $V_{\mathrm{j}}$ sensitivity may result from lowering the preference for fast $V_{\mathrm{j}}$ gating against slow $V_{\mathrm{j}}$ gating. This is consistent with our data on $I_{\mathrm{j}}$ deactivation kinetics, showing that the Cx43-tag lowers the relative contribution of fast $V_{\mathrm{j}}$ gating as indicated by the values of $I_{\mathrm{j} 1 \text {,inst }}$ and $I_{\mathrm{j} 2 \text {,inst }}$ derived from the biexponential decay of $I_{\mathrm{j}}$ (see Table 3 ). This raises the question of how to explain the increase in $g_{\mathrm{j}, \text { min }}$ instead of a decrease. A plausible assumption would

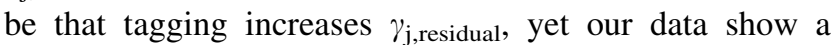
decrease (see Table 4). Alternatively, it may increase the channel mean open time as reported for CT-truncated Cx43 (Moreno et al. 2002) and thus elevate $g_{\mathrm{j}, \mathrm{min}}$.

V5/6-His tagging affects $\mathrm{Cx} 43$ channels beyond the phenomena attributable to fast $V_{\mathrm{j}}$ gating. Relevant are the effects on kinetics of $I_{\mathrm{j}}$ deactivation and channel conductance. Concerning kinetics, it affects $\tau_{\mathrm{d} 1}$ to accelerate $I_{\mathrm{j}}$ deactivation at $50 \mathrm{mV}<\left|V_{\mathrm{j}}\right|<100 \mathrm{mV}$ and decelerate at $50 \mathrm{mV}>\left|V_{\mathrm{j}}\right|>100 \mathrm{mV}$, giving rise to a decrease in $V_{\tau}$ and an increase in $\tau_{\mathrm{d}, 0}$ (see Table 2). Hence, the Cx43-tag alters the kinetics of the fast component. Conceivably, changes in structure and/or electric charge of V5/6-His-tagged CT may interfere with this process, directly or indirectly. Unfortunately, our experiments yielded no reliable $\tau_{\mathrm{d} 2}$ data. Concerning channel conductance, tagging provokes a prominent decrease in $\gamma_{\mathrm{j} \text {,main }}$ and $\gamma_{\mathrm{j} \text {,residual }}$ (see Table 4). The concomitant change suggests a modification on the open channel pore. Since CT is not a key component of the ion-conducting pathway, a direct effect seems unlikely.

Examining 6-His-tagged $\mathrm{Cx} 43$ channels, Martinez et al. (2002) reached somewhat different results and conclusions. As to multichannel properties, their $g_{\mathrm{j}, \mathrm{ss}}=f\left(V_{\mathrm{j}}\right)$ graph also showed a lower voltage sensitivity and a larger $g_{\mathrm{j}, \min }$, but they ascribed these effects to changing access resistance. As to single channels, they observed no changes in unitary conductance. Overall, they concluded the "theoretical risk" of altered behavior of $\mathrm{Cx} 43$ is not given. Therefore, while our results are consistent with their multichannel data, our interpretation is not. Concerning single-channel data, our results deviate from theirs. The reason for this discrepancy is unclear. It may be due to the missing V5 epitope on their His tag.

\section{Electrical Properties of Cx40-Tag Channels}

V5/6-His tagging of $\mathrm{Cx} 40$ exerts moderate changes on multichannel properties and virtually none on single-channel properties. With regard to the former, it increases the $V_{\mathrm{j}}$ sensitivity of $I_{\mathrm{j}}$, as indicated by a smaller $V_{\mathrm{j}, 0}$ and a larger $z$, and elevates the residual conductance at large $V_{\mathrm{j}}$, as evidenced by a larger $g_{\mathrm{j}, \mathrm{min}}$. Hence, the directional changes on $V_{\mathrm{j}, 0}$ and $z$ are opposite to those of Cx43-tag (see Table 1). The larger $V_{\mathrm{j}}$ sensitivity may be explained by an increased preference of fast over slow $V_{\mathrm{j}}$ gating. However, our values of $I_{\mathrm{j} 1 \text {,inst }}$ and $I_{\mathrm{j} 2 \text {,inst }}$ show the opposite (see Table 3 ).

In wt-Cx 40 cell pairs, $I_{\mathrm{j}}$ deactivates biexponentially with time. In $\mathrm{Cx} 40$-tag pairs, it inactivates monoexponentially at $\left|V_{\mathrm{j}}\right| \leq 100 \mathrm{mV}$, giving rise to $\tau_{\mathrm{d} 1}$ data; however, at $\left|V_{\mathrm{j}}\right|>$ $100 \mathrm{mV}, I_{\mathrm{j}}$ shows a rapid decay followed by a slow transient increase, thus preventing standard analysis. Conceivably, this reflects a superposition of fast and slow $V_{\mathrm{j}}$ gating, putatively responding to positive and negative polarity, respectively (Bukauskas and Verselis 2004). Moreover, tagging of $\mathrm{Cx} 40$ alters $\tau_{\mathrm{d} 1}$, accelerating $I_{\mathrm{j}}$ deactivation prominently at $\left|V_{\mathrm{j}}\right|<80 \mathrm{mV}$ and marginally at $\left|V_{\mathrm{j}}\right| 80 \mathrm{mV}$, giving rise to an increase in $V_{\tau}$ and a decrease in $\tau_{\mathrm{d}, 0}$ (see Table 2). This implies that the Cx40-tag also affects the kinetics of the fast component. Conceivably, its accelerated deactivation contributes to the increased $V_{\mathrm{j}}$ sensitivity of $I_{\mathrm{j}}$. Since the Cx40-tag has nearly no effect on $\gamma_{\mathrm{j}, \text { main }}$ and $\gamma_{\mathrm{j} \text {,residual }}$ (see Table 4 ), the elevated $g_{\mathrm{j}, \text { min }}$ cannot be ascribed to a change in $\gamma_{\mathrm{j}, \text { residual }}$. Alternatively, it may reflect an increase in $P_{\mathrm{o}}$. Overall, tagging of $\mathrm{Cx} 40$ exerts changes in channel properties different from those of $\mathrm{Cx} 43$.

It has been reported that $\mathrm{CT}$ truncation of $\mathrm{Cx} 40$ increased the $V_{\mathrm{j}}$ sensitivity of $I_{\mathrm{j}}$, decreased $g_{\mathrm{j}, \min }$ at large $V_{\mathrm{j}}$, impaired the fast component of $I_{\mathrm{j}}$ deactivation and wiped out $\gamma_{\mathrm{j}, \text { residual }}$ without affecting $\gamma_{\mathrm{j} \text {,main }}$ (Anumonwo et al. 2001). These changes resemble those seen in CT-truncated Cx43, with the differences that $g_{\mathrm{j}, \mathrm{ss}}$ is more sensitive to $V_{\mathrm{j}}$ and the effects are less prominent (see above). Likewise, when compared with $\mathrm{Cx} 43-\mathrm{tag}, \mathrm{Cx} 40$-tag channels give rise to an inverse directional change in $V_{\mathrm{j}}$ sensitivity of $I_{\mathrm{j}}$ but overall provoke less vigorous changes.

\section{Electrical Properties of Cx45-Tag Channels}

V5/6-His tagging of Cx45 leads to moderate effects on multi- and single-channel properties. As to multichannels, 
it decreases the $V_{\mathrm{j}}$ sensitivity of $I_{\mathrm{j}}$, as indicated by a larger $V_{\mathrm{j}, 0}$ and smaller $z$, and slightly decreases the residual conductance at large $V_{\mathrm{j}}$, as indicated by the smaller $g_{\mathrm{j}, \text { min }}$ (see Table 1). This pattern of modifications is reminiscent of lowering the relative preference for fast $V_{\mathrm{j}}$ gating. Qualitatively, it resembles the behavior of channels made of GFP-elongated Cx43 (Bukauskas et al. 2001) and CTtruncated Cx43 (Revilla et al. 1999). In contrast to $\mathrm{Cx} 43$ and $\mathrm{Cx} 40$, tagging of $\mathrm{Cx} 45$ has virtually no effect on $\tau_{\mathrm{d} 1}$, as evidenced by nearly unchanged values of $V_{\tau}$ and $\tau_{\mathrm{d}, 0}$ (see Table 2). As to single channels, tagging of $\mathrm{Cx} 45$ substantially decreases $\gamma_{\mathrm{j} \text {,main }}$ and $\gamma_{\mathrm{j}, \text { residual }}$ (see Table 4). The change in $\gamma_{\mathrm{j} \text {,residual }}$ tends to decrease $g_{\mathrm{j}, \min }$ and thus explains the observed modification of $g_{\mathrm{j}, \mathrm{min}}$. Hence, although less prominent, the responses of $\mathrm{Cx} 45$ channels to tagging resemble those of $\mathrm{Cx} 43$ channels.

\section{Mechanism of Action of V5/6-His Tag on Channel Properties}

When compared with truncated CT or GFP-elongated CT, the effects of V5/6-His-tagged Cxs are less prominent, suggesting that the latter represent graded, rather than allor-none, responses. In view of the diversity in CT modification, this is not surprising. V5/6-His tagging may cause subtle modifications in $\mathrm{Cx}$ structure and hence provoke less vigorous changes in channel properties.

Conceivably, the effects of V5/6-His tagging attributable to fast $V_{\mathrm{j}}$ gating arise from disturbed molecular interactions between the tagged-CT domain and a receptor site near the cytoplasmic channel mouth. This view emerges from a "particle-receptor" model of fast $V_{\mathrm{j}}$ gating (Moreno et al. 2002). In the case of Cx43-tag channels, a particle-receptor interaction during $V_{\mathrm{j}}$ gating could be hampered electrostatically and/or sterically. Comparison of the net charge distribution at putative particle and receptor sites of wt-Cx43 and Cx43-tags renders the former effect possible. Histidine residues in proteins carry one positive charge at $\mathrm{pH}_{\mathrm{i}}=7.2$; i.e., the $\mathrm{CT}$ of $\mathrm{Cx} 43$-tag terminates with six positive charges. Hence, a receptor located in the NT and/or CL region carrying a positive charge would permit molecular interactions with negative charges of the CT tail of wt-Cx43 but impair interactions with the CT tail of $\mathrm{Cx} 43-\mathrm{tag}$, thus enabling or impeding fast $V_{\mathrm{j}}$ gating, respectively. Interestingly, charge-substitution studies on CL of Cx43 have shown that position 142 is critically involved in fast $V_{\mathrm{j}}$ gating, lending support to a "ball-andchain" model (Shibayama et al. 2006). This concept may also apply to $\mathrm{Cx} 45$-tag and $\mathrm{Cx} 40$-tag channels. However, for the latter it needs modification to account for the observed inverse effect on fast $V_{\mathrm{j}}$ gating.

Mutations at sites significantly removed from areas putatively assigned to specific functions could still affect protein conformation and channel properties. We speculate that the changes in kinetics of $I_{\mathrm{j}}$ deactivation are conferred in this way. V5/6-His tagging may convert the tertiary structure of CT, impede the disposition of its particles to interact with receptors in the NT and/or CL region and thereby alter $\tau_{\mathrm{d} 1}$ as shown for $\mathrm{Cx} 43$-tag and $\mathrm{Cx} 40$-tags. The changes in unitary conductance of $\mathrm{Cx} 43$ and Cx45-tags could be entailed similarly. V5/6-His tagging may disrupt the formation of helix packing; alter the ion-conducting pathway given by areas of NT, M1/E1 and M3; and thereby modify current flow (Yeager and Harris 2007).

Acknowledgements We are grateful to Daniel Lüthi for expert technical assistance. This work was supported by the British Heart Foundation (grants PG/05/111 and PG/09/012/26846) and the Swiss National Science Foundation (grants 31-67230.01 and 31-108175.05).

Open Access This article is distributed under the terms of the Creative Commons Attribution Noncommercial License which permits any noncommercial use, distribution, and reproduction in any medium, provided the original author(s) and source are credited.

\section{References}

Anumonwo JMB, Taffet SM, Gu H, Chanson M, Moreno AP, Delmar M (2001) The carboxyl terminal domain regulates the unitary conductance and voltage dependence of connexin 40 gap junction channels. Circ Res 88:666-673

Bruzzone R, White TW, Paul DL (1996) Connections with connexins: the molecular basis of direct intercellular signalling. Eur $\mathrm{J}$ Biochem 238:1-2

Bukauskas FF, Verselis VK (2004) Gap junction channel gating. Biochim Biophys Acta 1662:42-60

Bukauskas FF, Jordan K, Bukauskiene A, Bennett MVL, Lampe PD, Laird DW, Verselis VK (2000) Clustering of connexion 43enhanced green fluorescent protein gap junction channels and functional coupling in living cells. Proc Natl Acad Sci USA 97:2556-2561

Bukauskas FF, Bukauskiene A, Bennett MVL, Verselis VK (2001) Gating properties of gap junction channels assembled from connexin 43 and connexin 43 fused with green fluorescent protein. Biophys J 81:137-152

Chen-Izu Y, Moreno AP, Spangler RA (2001) Opposing gates model for voltage gating of gap junction channels. Am J Physiol Cell Physiol 281:C1604-C1613

Coppen SR, Dupont E, Rothery S, Severs NJ (1998) Connexin45 expression is preferentially associated with the ventricular conduction system in mouse and rat heart. Circ Res 82:232-243

Coppen SR, Kaba RA, Halliday D, Dupont E, Skepper JN, Elneil S, Severs NJ (2003) Comparison of connexin expression patterns in the developing mouse heart and human foetal heart. Mol Cell Biochem 242:121-127

Desplantez T, Halliday D, Dupont E, Weingart R (2004) Cardiac connexins $\mathrm{Cx} 43$ and $\mathrm{Cx} 45$ : formation of diverse gap junction channels with diverse electrical properties. Pfluegers Arch 448: 363-375

Desplantez T, Dupont E, Severs NJ, Weingart R (2007) Gap junction channels and cardiac impulse propagation. J Membr Biol 218: $13-28$ 
Dupont E, el Aoumari A, Roustiau-Severe S, Briand JP, Gros D (1988) Immunological characterization of rat cardiac gap junctions; presence of common antigenic determinants in heart of other vertebrate species and in various organs. J Membr Biol 104:119-128

Dupont E, Ko YS, Rothery S, Coppen SR, Baghai M, Haw M, Severs NJ (2001) The gap-junctional protein, connexin40, is elevated in patients susceptible to post-operative atrial fibrillation. Circulation 103:842-849

Giepmans BN, Moolenaar WH (1998) The gap junction protein connexin 43 interacts with the second PDZ domain of the zona occludens-1 protein. Curr Biol 8:931-934

Halliday D, Dupont E, Coppen SR, Severs NJ (2003) Development of a cell model for functional and structural analysis of connexin co-expression: achieving homogeneous and inducible expression of multiple connexins in stable transfectants. Cell Commun Adhes 10:311-317

Harris AL (2001) Emerging issues of connexin channels: biophysics fills the gap. Q Rev Biophys 34:325-472

Haubrich S, Schwarz H-J, Bukauskas FF, Lichtenberg-Fraté H, Traub O, Weingart R, Willecke K (1996) Incompatibility of connexon 40 and 43 hemichannels in gap junctions between mammalian cells is determined by intracellular domains. Mol Biol Cell 7:1995-2006

Hunter AW, Barker RJ, Zhu C, Gourdie RG (2005) Zonula occludens-1 alters connexin43 gap junction size and organization by influencing channel accretion. Mol Biol Cell 16:5686-5698

Kreuzberg MM, Söhl G, Kim J-S, Verselis VK, Willecke K, Bukasukas FF (2005) Functional properties of mouse connexin30.2 expressed in the conduction system of the heart. Circ Res 96:1169-1177

Kreuzberg MM, Liebermann M, Segschneider S, Dobrowolski R, Dobrzynski H, Kaba R, Rowlinson G, Dupont E, Severs NJ, Willecke K (2009) Human connexin31.9 unlike its orthologous protein connexin 30.2 in the mouse, is not detectable in the human cardiac conduction system. J Mol Cell Cardiol 46:553-559

Laing JG, Manley-Markowski RN, Koval M, Civitelli R, Steinberg TH (2001) Connexin45 interacts with zonula occludens- 1 and connexin43 in osteoblastic cells. J Biol Chem 276:23051-23055

Martinez AD, Hayrapetyan V, Moreno AP, Beyer EC (2002) Connexin43 and connexin45 form heteromeric gap junction channels in which individual components determine permeability and regulation. Circ Res 90:1100-1107
Moreno AP, Chanson M, Anumonwo J, Scerri I, Gu H, Taffet SM, Delmar M (2002) Role of the carboxyl terminal of connexin 43 in transjunctional fast voltage gating. Circ Res 90:450-457

Revilla A, Castro C, Barrio LC (1999) Molecular dissection of transjunctional voltage dependence in the connexin-32 and connexin-43. Biophys J 77:1374-1383

Sakai R, Elfgang C, Vogel R, Willecke K, Weingart R (2003) The electrical behaviour of rat connexin $\mathrm{Cx} 46$ gap junction channels expressed in transfected HeLa cells. Pfluegers Arch 446:714-727

Sambrook J, Fritsch EF, Maniatis T (1989) Molecular cloning, a laboratory manual, 2nd edn. Cold Spring Harbor Laboratory Press, New York

Severs NJ, Rothery S, Dupont E, Coppen SR, Yeh HI, Ko YS, Matsushita T, Kaba R, Halliday D (2001) Immunocytochemical analysis of connexin expression in the healthy and diseased cardiovascular system. Microsc Res Tech 52:301-322

Severs NJ, Dupont E, Coppen SR, Halliday D, Inett E, Baylis D, Rothery S (2004) Remodelling of gap junctions and connexin expression in heart disease. Biochim Biophys Acta 1662: $138-148$

Shibayama J, Gutiérrez C, González D, Kieken F, Seki A, Carrión JR, Sorgen PL, Taffet SM, Barrio LC, Delmar M (2006) Effect of charge substitutions at residue His-142 on voltage gating of connexin43 channels. Biophys J 91:4054-4063

Sohl G, Willecke K (2004) Gap junctions and the connexin protein family. Cardiovasc Res 62:228-232

Terpe K (2003) Overview of tag protein fusions: from molecular and biochemical fundamentals to commercial systems. Appl Microbiol Biotechnol 60:523-533

Toyofuku T, Yabuki M, Otsu K, Kuzuya T, Hori M, Tada M (1998) Direct association of the gap junction connexin-43 with ZO-1 in cardiac myocytes. J Biol Chem 273:12725-12731

Valiunas V, Manthey D, Vogel R, Willecke K, Weingart R (1999) Biophysical properties of mouse connexin30 gap junction channels studied in transfected human HeLa cells. J Physiol 519:631-644

Van Veen AA, van Rijen HV, Opthof T (2001) Cardiac gap junction channels: modulation of expression and channel properties. Cardiovasc Res 51:217-229

Yeager M, Harris AL (2007) Gap junction channel structure in the early 21st century: facts and fantasies. Curr Opin Cell Biol 19:521-528 